\title{
Physical Imagery: Kinematic versus Dynamic Models
}

\author{
Daniel L. Schwartz
}

\section{Vanderbilt University}

\begin{abstract}
Physical imagery occurs when people imagine one object causing a change to a second object. To make inferences through physical imagery, people must represent information that coordinates the interactions among the imagined objects. The current research contrasts two proposals for how this coordinating information is realized in physical imagery. In the traditional kinematic formulation, imagery transformations are coordinated by geometric information in analog spatial representations. In the dynamic formulation, transformations may also be regulated by analog representations of force and resistance. Four experiments support the dynamic formulation. They show, for example, that without making changes to the spatial properties of a problem, dynamic perceptual information (e.g., torque) and beliefs about physical properties (e.g., viscosity) affect the inferences that people draw through imagery. The studies suggest that physical imagery is not so much an analog of visual perception as it is an analog of physical action. A simple model that represents force as a rate helps explain why inferences can emerge through imagined actions even though people may not know the answer explicitly. It also explains how and when perception, beliefs, and learning can influence physical imagery. (c) 1999 Academic Press
\end{abstract}

People solve spatial problems about shape, position, change of perspective, and navigation. People also solve physical problems about forces, resistances, and how one object causes changes to another. To a large extent, research on physical problem solving has emphasized people's beliefs and qualitative theories about physical behaviors, and research on spatial problem solving has emphasized people's analog representations of visual perception. As a consequence, research relevant to analog representation has generally investigated spatial and visual issues but not physical and haptic issues. This seems like an omission. Imagine, for example, running wall-towall in a breezy room and then imagine running wall-to-wall in waist deep water. Even though many of the spatial relations are identical, the effect of imagined resistance is introspectively compelling. Less introspectively,

Sashank Varma was an invaluable source of ideas. I thank John Rieser and Howard Sandler for many productive conversations. I also thank several anonymous reviewers for their patience and detailed commentary.

Address correspondence and reprint requests to Daniel L. Schwartz, Box 512-GPC, Vanderbilt University, Nashville, TN 37203. E-Mail: dan.schwartz@ vanderbilt.edu. 
Hegarty (1992) found that people can mentally animate a pulley system forward in time more easily than they can animate it backward (e.g., starting with a pull on the rope versus starting with the resulting rise of the block). Despite the fact that the relevant spatial relations are the same either way, people did better when operating in the direction of physical forces (see also, Freyd, 1987). The following experiments examine whether and how people represent physical properties in analog format, or as it will be called here, physical imagery. The next section describes a task suited to this investigation. Afterward, two broad models of imagery, kinematic and dynamic, are developed and applied to this task. In the General Discussion the broader implications of these two models are developed to suggest that current models of imagery are overly committed to visual perception instead of physical action.

\section{A TASK FOR INVESTIGATING PHYSICAL IMAGERY}

To investigate how people incorporate physical information into their ana$\log$ representations, it is important to find a physical problem for which people are clearly using imagery. There is a history of dispute over whether various psychological phenomenon are truly the result of an analog representation, or whether people are simulating analog-like outcomes by using beliefs (e.g., Finke \& Freyd, 1989; Kosslyn, 1976; Pylyshyn, 1973, 1981). A belief (or proposition as it is often called) is a claim; for example, "I take 8 seconds to walk 30 yards." An analog representation (or analog imagery as it is often called) simulates a sequence of intermediate states that are analogous to what one might perceive when completing an action like walking 30 yards. To see the basis for the dispute, suppose that subjects in an experiment take a specific amount of time to infer how long it will take them to walk 30 yards. Also suppose that when subjects are told they will be carrying a heavy backpack, it takes them longer to make their inference (Decety, Jeannerod, \& Prablanc, 1989; Intons-Peterson \& Roskos-Ewoldsen, 1989). An analog characterization of this backpack effect might be that people incorporate weight information into their imagery. The imagined weight of the backpack slows down the real-time operations of their analog representation, and people take longer to complete each step of their imaginary walk. Alternatively, people may simply believe that they walk slower when carrying a load, and they tacitly assume they should wait awhile before they tell the experimenter that they are done. In the analog characterization, the effect of the backpack on walking time emerges as people imagine themselves moving through the intermediates states of their journey. In the belief characterization, the effect of the backpack is inferred prior to any imagery (if there is any) and the representation of the intermediate states is irrelevant. Often times, it is difficult to say which characterization is correct.

One way that researchers have shown that beliefs are not driving apparent 
imagery is to demonstrate that key behavioral outcomes are impervious to people's beliefs (e.g., Finke \& Freyd, 1989; Pylyshyn, 1981). One might show, for example, that regardless of whether people believe they walk faster or slower carrying a weight, they always take longer to infer the time required to walk 30 yards when told they will carry a heavy backpack. Demonstrations along these lines have been useful in establishing that imagery involves a distinct representational code. Sometimes, however, researchers take the extra step of assuming that if people's beliefs can influence their imagery operations, then those operations cannot be truly analog. This assumption is problematic for physical imagery. For physical problems, one would ideally expect people's beliefs to influence their imagery. Beliefs can provide important information about invisible physical properties. When imagining the bounce of a ball, it is useful to know whether the interior is made of rubber, glass, or feathers. For physical problems, imperviousness to beliefs is too restrictive a criterion for deciding whether a psychological process is analog or propositional.

For situations where it is reasonable to suppose that beliefs can influence imagery, a useful method for verifying the presence of imagery is to show that people do not have beliefs that could fully imitate imagery outcomes (e.g., Finke, 1985; Kosslyn, 1980). Krist, Fieberg, and Wilkening (1993), for example, showed that 5-year-olds do not correctly answer questions about where an object will land if it is pushed off a ledge. Children believe that the higher an object's release point, the faster it must be pushed to reach a given target. Yet, when asked to push an object, they correctly modify the force of their pushing actions to compensate for height adjustments. The physical problem used in the following experiments extends this type of evidence to a task that more clearly involves imagery.

Consider two cylindrical glasses of equal height. One is a thin glass, and one is a wide glass. Each glass has a line indicating the same level of imaginary water. There are two versions of the problem. In the belief version, people answer the explicit question of whether water in the glasses would pour at the same or different angle. In the tilting condition, people close their eyes and in succession tilt each glass until they imagine that the pretend water reaches the rim. Across several experiments, less than $15 \%$ of people made the correct explicit judgment, whereas nearly $100 \%$ correctly tilted a thin glass farther than a wide glass (Schwartz \& Black, 1999). When examined more closely, people's beliefs were not only wrong, they were qualitatively backward. When asked to draw a water line on a target glass so that it would pour at the same angle as a standard glass, people drew their water levels higher for wide glasses and lower for thin ones. The true answer is that to pour at the same angle a thin glass needs a higher water level than a wide one. Interestingly, people did not exhibit a "naive theory" for this consistent error; across problems, they often changed their justifications and the problem features they considered important. The same individual, for example, argued 
that a thin glass fills with water faster so it should empty faster, and then subsequently argued that the water had the same distance to travel in each glass, so the glasses should pour at the same time. It seems very unlikely that conflicting and incorrect beliefs can be responsible for the accurate tilting.

In addition to eliminating beliefs, the experiments examined other nonimagery alternatives. People did not solve the problem by recalling identical experiences; people accurately tilted unusual glasses like cones, inverted cones, and boxes. The results also showed that the tilting accuracy was not due to overt physical activity (e.g., Aglioti, Desouza, \& Goodale, 1995; Bridgeman, 1992; Turvey, Solomon, \& Burton, 1989). People completed the task successfully in the imagination without concurrent motor action. Individuals looked at a glass with a line indicating its water level. They closed their eyes and imagined the glass tilting until the water reached the rim. Their hands remained flat on the table. It was only when they said they had completed the imagined tilt that they were allowed to move their hands. With their eyes still closed, they positioned a stick in mid-air as though it were a lid on the glass in their imagination. The angle of the imagined glass was read from the stick. Across four different water levels, people always imagined tilting a narrow glass farther than a wide one. And, showing that the imagery was analog in the sense of capturing quantitative rather than just qualitative information, people tilted the glasses farther when they had lower water levels. All in all, the evidence supported the interpretation that people solve the water pouring problem through some form of analog imagery. The question, then, is what form of imagery.

\section{KINEMATIC AND DYNAMIC MODELS OF PHYSICAL IMAGERY}

There are two broad classes of physical imagery that will be contrasted: the kinematic model (KM) and the dynamic model (DM). KM represents only spatial relations, whereas DM also includes force representations. One may preview their differences by considering the problem of designing a stable robot. A kinematic solution is to use a four-legged robot that keeps three feet on the ground each time it takes a step. The robot maintains its balance by ensuring that its center point remains within the triangle made by the three feet on the ground (McGhee, 1983). This is a kinematic solution because it only uses spatial relations and does not represent dynamic properties like momentum. Kinematic robots, for example, need to move slowly because they cannot anticipate the toppling that might occur if they stop suddenly from a high speed. In contrast, dynamic solutions rely on forces to maintain equilibrium, as in the case of a one-legged robot that bounces back and forth to stay upright (Raibert, 1986).

\section{The Kinematic Model}

In physics, kinematics refers to, "The descriptions of motions ... without regard to the forces that may control the motion'" (p. 444; Mills, 1994). 
Galileo and Copernicus used kinematic descriptions. They described the spatial behaviors of projectiles and planets but did not invoke causal forces like gravity to explain those behaviors. In psychology, KM proposes that imagery holds geometric (shape, size, position) information that can be animated and inspected by a handful of basic spatial operations. Shepard (1984, 1994), for example, has argued that imagery is fundamentally kinematic and does not represent dynamic information. Similarly, Kosslyn's (1980) computational model of imagery included an analog spatial array that gave metric properties to thoughts, but the array did not represent any invisible or dynamic components like a push or pull.

Kinematic models have been designed to describe how people represent single objects or spatial relationships among objects. Even so, they can be extended to portray physical interactions between two objects. They do this by supplementing imagery with a selection process that chooses which spatial relationships to change and which to hold constant during image transformation. This selection of transformations comes from outside the image itself because the image only includes geometric information. Imagine, for example, determining the behavior of two tires that touch each other like gears. There is nothing in the geometry of this image that determines how the tires should move relative to one another. One needs to consider friction to determine that they turn in opposite directions when given a spin. However, once one knows what type of spatial transformations to apply, one can then model the tires' behaviors kinematically, for example, by ensuring a point-for-point rotation at the tires' point of contact. An example of this approach may be found in the work of Forbus, Nielsen, and Faltings (1990). They describe a computer simulation in which qualitative rules make an inference about how things should behave, and then those behaviors are portrayed in a spatial array. This type of model uses imagery to hold spatial, not physical, information. Therefore, the functional inferences that determine physical interactions are not drawn through imagery; instead, they are prespecified.

There are many examples in which people's ability to imagine physical events has been explained with a kinematic model (e.g., Shepard \& Cooper, 1986; Olivier, Nakata, \& Landon, 1996). Simply showing that people use imagery to model a physical event does not necessarily show that an image is representing force information (e.g., Sims \& Hegarty, 1997). Leyton (1989), for example, showed that a few well-chosen geometric principles could explain how people infer the deforming effects of pressure to a nonrigid object. As a second example, McAfee and Proffitt (1991) argue that it is not a misunderstanding of gravity that prevents people from realizing that a water surface remains horizontal in a tilted glass. Instead, it is people's use of a glass-based, rather than a horizon-based, frame of reference that explains why they make errors on the Piagetian water level task. And, as one more example, Parsons (1994) asked people to judge whether a human hand shown on a screen was a left or right hand. People imagined moving their own hand to the position of the hand on the screen, and their latencies 
reflected imagined movements that took into account the physical constraints of joints and muscles. Parsons speculated that people use a "forward kinematic map of the arm to make small changes in the joint angles"' (p. 726). In other words, people do not represent the physical constraints in imagery, people represent the spatial implications of those constraints in a map.

The solution to the water pouring problem may also be explained kinematically. If we assume that people can select this correct transformation despite their faulty beliefs, people can rotate the glass until the rim and the original mid-point of the water align horizontally. It is not necessary to model the water deformation or the physical forces that regulate this deformation. People might simply rotate a shape to a spatially defined target.

\section{The Dynamic Model}

A dynamic model (DM) of imagery represents dynamics in the physicist's sense: "The way in which the motion of a mechanical system is governed by the forces acting'" (p. 432, Mills, 1994). Kepler and Newton used dynamic descriptions. Kepler, for example, introduced the idea that the sun exerts a force that causes the trajectory of the planets (Gentner et al., 1997). A central property of DM is the direct representation of rate. DM distinguishes itself from KM both because it includes force and resistance information and because it depends on rate representations to model that information. In Newtonian physics, for example, force is defined in terms of the rate of acceleration $(F=m a)$. Problems involving changes to a ball's movement are solved by determining how an impinging rate, like the force of gravity or a colliding body, influences the ball's rate of displacement. This differs from kinematic approaches that use statically specified spatial relations to determine object movement. Galileo, for example, described constant acceleration with ratios of distances. (He did not have the benefit of algebra for representing rates like velocity over time; Drake, 1989.) In psychology, DM claims that an image not only represents spatial matters, it also represents analogs of physical properties as rates that guide imagined object interactions.

There is some prior research that supports DM, but this research does not determine whether people can use analog representations of physical information to solve everyday problems like how water behaves in a tilting glass. The studies that support DM have included tasks involving self motion (Parsons, 1994), biological motion (Shiffrar \& Freyd, 1990), friction (Hubbard, 1995) and momentum (Freyd \& Johnson, 1987). These studies emphasize universal physical properties or biological properties, and the researchers often claim the results are due to inherent constraints on imagery (e.g., Gilden, 1991; Proffitt, Kaiser, \& Whelan, 1990; Shiffrar, 1994). Consequently, there is little evidence that people can represent, or strategically recruit, the context-specific information needed to solve a problem like how a ball bounces depending on its substance.

There are several computational models, however, that do suggest how 
people might represent context-specific dynamic information. Schwartz and Black (1996a), for example, proposed an enactive representation called a depictive model. A depictive model relies on rate-based representations of physical properties like friction (Schwartz \& Black, 1996a), elasticity (Gardin \& Meltzer, 1989), and balance (Funt, 1980). The representations enforce the speed and direction with which one object reponds to the movement of another object during a mental simulation. To model touching tires, for example, a "high friction" representation could cause the surface of tire A to push the surface of tire B at the same rate and in the same direction, whereas a "slippery" representation would allow tire B to turn more slowly (Schwartz \& Black, 1996a).

For the pouring task, people's imagery might have represented the following physical constraints: liquids conform to their containers, objects are "pulled" in the direction of gravity, and volume is conserved. As the glass tilts, the conformity and gravity constraints cause the imagined water to "spread" at a certain rate against the side of the glass closest to the ground. The conservation of volume constraint ensures that when the water spreads toward the rim on one side of the glass, it retreats along the other side at the same rate. As a result, the mid-point of the water surface becomes an axis separating the advancing and retreating water. The radius from the axis to the glass side is shorter in the thin glass than the wide one. Figure 1 shows that for the same degree of rotation, the edge of the water advances more slowly for a small radius than a large one. As a result, people turn the thin glass farther because it takes longer for the water to advance to the rim in their imagination.

\section{APPLYING KM AND DM TO THE WATER POURING TASK}

The contrast between KM and DM may be sharpened with a formalism that specifies a partial water pouring solution that works for either model. The formalism is not intended as a description of an actual cognitive process, although it can readily be translated into more intuitive KM and DM solutions such as those above. Rather, it is a way to highlight the main assumptions of KM and DM. As a simplification, the formalism reduces the problem to two dimensions and focusses on a triangular portion of water within each glass. Panel a of Fig. 2 shows a thin glass and a wide glass, each with an inscribed triangle that is proportional to glass width. Assume two primary constraints on changes to the triangles. The first is that the area cannot change (volume is conserved). When a triangle lengthens, it must narrow proportionally. The second is that side $\mathbf{B}$ of a triangle must be adjacent to the glass (water conforms to its container). With some minor additions shown in Fig. 2 , these constraints model the fact that the water "stretches faster" to the rim of a wide glass than of a thin one. Panel b of Fig. 2 shows that when the length of side $\mathbf{C}$ is reduced by half for each glass, the water reaches the 


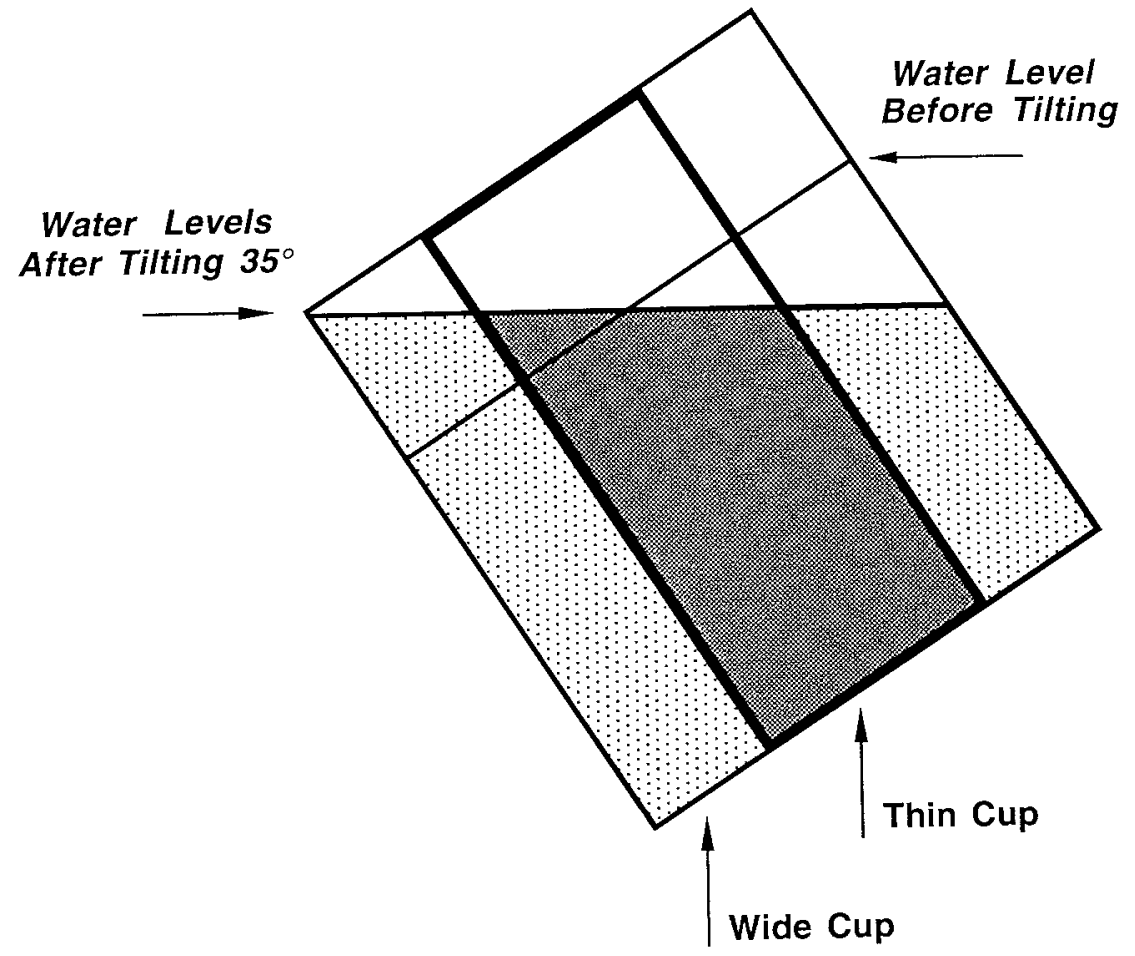

FIG. 1. A thin glass set in a wide glass shows that glass diameter affects the angle at which a liquid pours.

rim of the wide glass, but not the thin one. Notice that this solution works even if the glasses are not rotated. As long as side $\mathbf{C}$ is affected the same way for both glasses, the results will always put the vertex at the rim of the wide glass before the thin glass. Even if people make the common error of believing that water does not reside horizontally in a tilted glass (e.g., Pascual-Leone \& Morra, 1991), they should still tilt the thin glass farther than the wide one. Thus, there is some flexibility in how people can determine the relationship between the rate that the triangle stretches and the behavior of the glass.

Both KM and DM can model the effect of glass width using this formalism. The issue that divides the two models is how they determine the rate at which the triangle stretches toward the rim. KM depends on spatial relations to regulate the rate of stretching. One correct kinematic solution, shown in panel $\mathbf{c}$, ensures that side $\mathbf{A}$ and the horizon maintain a constant angle during rotation. Other solutions, varying in levels of absolute accuracy, can be found by aligning different spatial features and angles within the system (Hecht \& Proffitt, 1995; McAfee \& Proffitt, 1991). 
(a)

- The triangles are proportional to the glass width.

- The area of a triangle remains constant.

- Side $B$ remains flush with glass.

- Vertex BC anchored to glass.

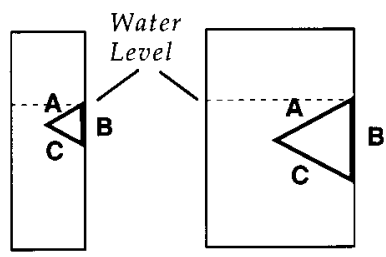

(b)

- Keep side A congruent with side B.

- Reduce side $C$ by $1 / 2$ in each glass.
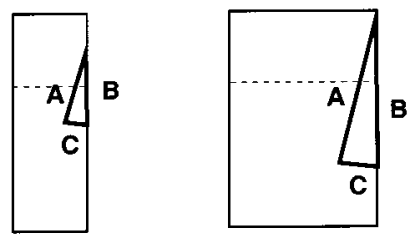

(c)

- Keep the Horizon and side A at a constant angle during rotation (a correct solution).

- Rotate until triangle reaches rim in either glass.

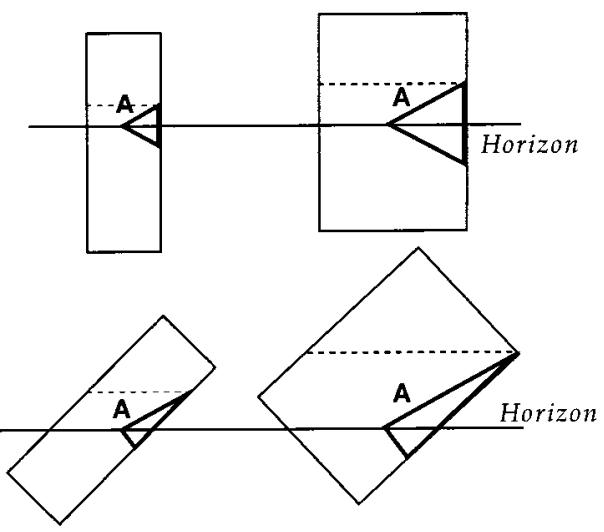

FIG. 2. A kinematic solution to the water pouring task: (a) defining a set of constraints on a triangular portion of the water, (b) reducing side $\mathrm{C}$ puts triangle at rim of wide glass before thin glass, (c) adding a kinematic constraint so the triangles respond to rotation.

According to DM, the rate of "triangle stretching" can be regulated by non-spatial information. In particular, the change of the triangle and the glass can be coupled by dynamic constraints on relative rates of change. While spatial relations are important, I accentuate dynamic constraints by representing the coupling with the inherently temporal expression

$\Delta$ water transformation $\leftrightarrow \Delta$ glass transformation.

People try to coordinate the rates of change between the water and glass. 
For "5 units" of tilting change, perhaps the water responds with "5 units" of stretching change. Importantly, the rates of change can capture nonspatial elements. For example, given the same distance of tilt, a heavy glass may generate more units of change than a light glass (e.g., in terms of work). Consequently, even though the spatial behaviors of the two glasses can be identical, the imagined water might stretch more for the heavy glass.

To summarize, for KM, maintaining a spatial relation determines a rate of change. For DM, a coordination of rates helps determine a spatial relation. To put it another way, KM requires individuals to monitor how far they tilt a glass, whereas DM requires individuals to monitor how fast or hard they tilt a glass (during which the distance of the tilt can go unmonitored, see Schwartz \& Black, 1999).

The plan for discriminating $\mathrm{KM}$ and DM in the these experiments is to manipulate people's beliefs and perceptual input to their imagery. The two models make distinct predictions. Broadly expressed, KM proposes that an image only includes information about spatial relations and their maintenance or achievement through movement. Therefore, beliefs and perceptions should modify imagery only when they change the spatial information, spatial expectations, or the coordinate system incorporated into the content of an image (e.g., McAfee \& Proffitt, 1991; Sholl \& Liben, 1995; Tversky \& Schiano, 1989). DM proposes that an image also includes information about physical constraints on rate. Therefore, it predicts that beliefs and perceptions about rates should change the operations of an image, even if spatial expectations and information are held constant. The specific predictions are developed within the context of each experiment. Experiments 1 and 2 test the predictions of KM and DM for two situations where beliefs are manipulated. Experiments 3 and 4 compare the two models for situations where perceptual information is manipulated.

\section{EXPERIMENT 1: BELIEFS ABOUT SPATIAL OUTCOMES USURP PHYSICAL IMAGERY}

The current study examines how imagery changes when people try to specify the spatial outcome of an imagined physical interaction based on their beliefs. According to KM, imagery can be controlled by selecting particular spatial relations to maintain or target. This selection can occur on the basis of one's beliefs. There is a large body of research, for example, that shows people can construct images based on verbal concepts (e.g., Chase \& Clark, 1972; Hegarty \& Just, 1993; Kosslyn, 1980). For the water pouring task, the angle of the glass is a key spatial outcome. Consequently, people's beliefs about the final angle of a glass should guide their subsequent imagery so that it meets that spatial target. For example, if people believe the wide and thin glasses should tilt to the same angle, then they will make their imagery do just that. 
According to DM, the amount that people tilt a glass arises from rate representations that constrain the speed of the water's response to the movement of the glass. If this is correct and rate representations enable people to use their physical imagery successfully, then the attempt to target a particular angle or spatial outcome should be destructive to physical imagery. The attempt to target the final angle should usurp the natural rate-based operation of physical imagery so that the correct relative angles of the glasses cannot emerge from the tilting movement. Moreover, if the achievement of a specific angle in physical imagery normally emerges from rate representations, then people may not be very good at coordinating their moving imagery with a static spatial solution they believe to be correct. For example, people may believe that the glasses should be tilted to the same angle without ever considering which angle. Because the rate representations are not available for determining which angle it should be, people may have trouble coordinating their imagery across the wide and thin glass. Consequently, they may show haphazard tilts that are both incorrect and that do not correspond to their explicit beliefs.

To test these two alternatives, participants completed the water pouring task in one of two orders. In the Tilt $\rightarrow$ Judge order, people tilted a thin and wide glass each containing imagined water. Afterward, they made an explicit judgment whether the two glasses would start pouring at the same or different angles. This replicates the procedure used in the experiments reported earlier. In the Judge $\rightarrow$ Tilt order, people first made the explicit judgment and then tilted the two glasses. The assumption was that asking people to judge the glasses first would make them explicitly conscious of the outcome of glass angle. According to KM, this focus on a spatial outcome may influence their imagery to implement this outcome. Therefore, there should be a correspondence between people's explicit judgments, right or wrong, and their tilts. In contrast, according to DM, the attempt to implement a pre-specified spatial outcome will usurp the action of the rates that enables people to achieve their tilts through imagery. Consequently, they will not be able to solve the problem accurately through imagery, and their beliefs may not provide sufficient precision to guide their imagery to a consistent (albeit wrong) solution.

\section{Method}

Participants. Twelve female and eight male undergraduate and graduate volunteers were randomly assigned in equal numbers to two conditions balancing for gender.

Materials. The thin and wide glasses had 3.2- and 8.4-cm diameters, respectively. Both were $10 \mathrm{~cm}$ tall and had the water level indicated with a piece of thin black tape $2.5 \mathrm{~cm}$ below their rims. Water pours at $60^{\circ}$ in the thin glass and $40^{\circ}$ in the wide glass. The thin glass was an irish coffee shot glass with a heavy base and a small handle near the bottom. The wide glass was a crystal coffee cup with a large handle and a slight curve at the base. 
Design and procedure. A between-subjects factor was the order the participants completed the following two phases. For the Tilt phase, participants grasped an empty cup with their thumb on the water line. They were told to tilt the cup with their eyes closed until the imaginary water just reached the rim. Before the participants opened their eyes, the experimenter measured the angle of the tilt and removed the cup from their hands. The process was repeated for the other cup. The order of the two cups was counter-balanced across subjects. For the Judge phase, participants saw the two cups attached to a board side-by-side. Participants were told, "These two glasses are glued to this board. Imagine that each glass has water to the level of the black line. If I were to tip the board toward you, do you believe that the water would start pouring out of the glasses at the same time or different times.' If they said different times, they specified which would pour first. Participants did not touch the board. They did not receive feedback in either phase.

Results

Only 1 of 20 people correctly judged that a wide glass pours before a narrow glass. This replicates prior findings (Schwartz \& Black, 1999). The new question for this experiment is how the explicit judgment about a spatial outcome would affect people's subsequent imagery. In Fig. 3, each line con-

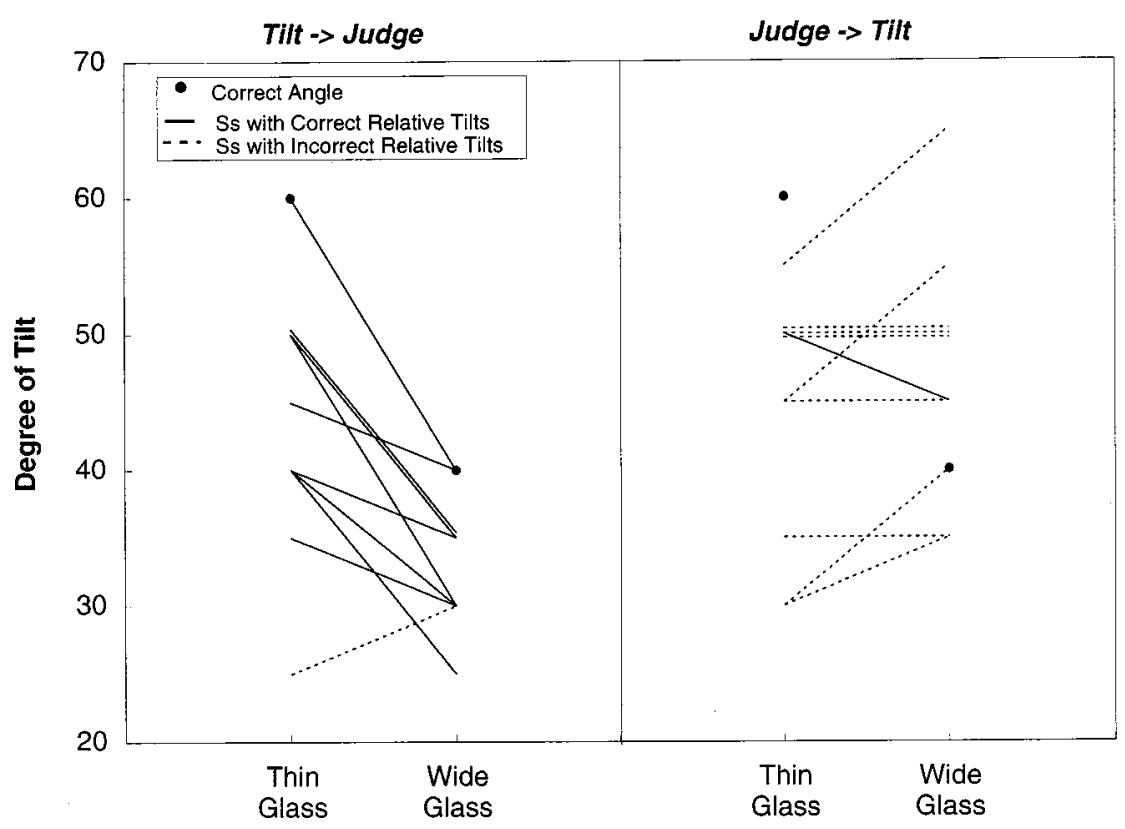

FIG. 3. Thinking about a spatial outcome interferes with subsequent physical imagery (Experiment 1). 
nects an individual's tilts for the thin and wide glasses. A solid line indicates a person who correctly tilted the thin glass farther than the wide one, and a dotted line indicates a person who did not. As found previously, individuals in the Tilt $\rightarrow$ Judge condition tended to under tilt, but still correctly tilted the thin glass $\left(M=43.5^{\circ}, S D=9.7\right)$ farther than the wide one $\left(M=33.0^{\circ}\right.$, $S D=4.8)$. In contrast, individuals in the Judge $\rightarrow$ Tilt condition did not tilt the thin glass $\left(M=44.0^{\circ}, S D=9.1\right)$ farther than the wide one $\left(M=47.0^{\circ}\right.$, $S D=9.2)$. This effect is reflected in a significant task order by glass width interaction; $F(1,18)=19.7, M S e=23.13, p<.01$.

The Judge $\rightarrow$ Tilt outcome would fit KM if people's tilts matched their judgments. This is because their beliefs about spatial outcomes would have guided their imagery. This did not happen. Although people's initial judgments influenced their subsequent tilts, the effect was to interfere with, rather than guide, their imagery. Not only did individuals in the Judge $\rightarrow$ Tilt condition make incorrect tilts, they did not make their tilts fit their beliefs either. Table 1 shows that the individuals' tilts were generally not associated with their judgments in either condition. The lack of association was tested by treating people's explicit judgments as a between-subjects factor that was crossed with task order. Only one individual thought the wide glass poured sooner and was excluded from this analysis. This left the two judgment levels of thin first and same time. The dependent measures were the individuals' two tilts. The judgment factor is not significant as a main effect; $F(1,15)$ $=.07, M S e=135.7, p>.7$, nor in interaction with the difference between the tilts of the two glasses; $F(1,15)=.06, M S e=26.5, p>.8$; nor in the three-way interaction of relative tilt, task order, and judgment; $F(1,15)=$ $0.0, p>.9$. When isolating the Judge $\rightarrow$ Tilt condition, the evidence suggests that people were either unable or unwilling to make their subsequent tilts fit their judgments; the relative tilt by judgment interaction is not significant;

TABLE 1

Average Degree of Tilt for Each Glass Broken out by Judgment and Condition

\begin{tabular}{|c|c|c|c|c|c|c|}
\hline \multirow[b]{2}{*}{ Degree of tilt: } & \multicolumn{3}{|c|}{$\begin{array}{c}\text { Condition: Tilt } \rightarrow \text { Judge } \\
\text { Frequency of beliefs } \\
\text { about which pours first }\end{array}$} & \multicolumn{3}{|c|}{$\begin{array}{c}\text { Condition: Tilt } \rightarrow \text { Judge } \\
\text { Frequency of beliefs } \\
\text { about which pours first }\end{array}$} \\
\hline & $\begin{array}{l}\text { Wide } \\
\text { glass } \\
(n=1)^{a}\end{array}$ & $\begin{array}{l}\text { Thin } \\
\text { glass } \\
(n=3)\end{array}$ & $\begin{array}{l}\text { Same } \\
\text { time } \\
(n=6)\end{array}$ & $\begin{array}{l}\text { Wide } \\
\text { glass } \\
(n=0)\end{array}$ & $\begin{array}{l}\text { Thin } \\
\text { glass } \\
(n=4)\end{array}$ & $\begin{array}{l}\text { Same } \\
\text { time } \\
(n=6)\end{array}$ \\
\hline Thin glass & $35.0^{b}$ & 46.7 (11.5) & $43.3(9.8)$ & 一 & $43.8(9.5)$ & $44.2(9.7)$ \\
\hline Wide glass & 30.0 & $35.0(5.0)$ & $32.5(5.2)$ & - & $46.3(8.5)$ & $47.5(10.4)$ \\
\hline Difference $^{c}$ & 5.0 & $11.7(7.6)$ & $10.8(9.2)$ & - & $-2.5(6.5)$ & $-3.3(5.2)$ \\
\hline
\end{tabular}

${ }^{a} n$ is the number of individuals in the condition who made that explicit judgment.

${ }^{b}$ In degrees from upright. Parenthetical values are between-subjects standard deviations.

${ }^{c}$ Average of thin tilt minus wide tilt. A positive value indicates correct relative tilts. 
$F(1,8)=.05, M S e=16.2, p>.8$. Four of the individuals in the Judge $\rightarrow$ Tilt condition spontaneously mentioned that they tried to tilt in accordance with their judgments. These individuals did not show a superior fit between their judgments and relative tilts. The others were not asked.

\section{Discussion}

The results from the Tilt $\rightarrow$ Judge condition demonstrated that people have relatively accurate physical imagery for this task and that this imagery does not inform their inaccurate beliefs. In contrast, the results from the Judge $\rightarrow$ Tilt condition demonstrated that people's beliefs can affect their imagery. In the Judge $\rightarrow$ Tilt condition people's initial judgments caused inaccurate tilting. Interestingly, the beliefs interfered with, rather than guided, the imagery in the tilting phase. Not only were people's tilts wrong, people did not even make their tilts fit their incorrect judgments. For example, individuals who believed the two glasses would pour at the same angle did not tilt them differently than individuals who believed the thin glass would pour first. Perhaps, the reason people were so bad in this context is that their qualitative beliefs did not represent enough detail about the target angles. For example, people may have judged that the glasses would pour at the same angle without wondering which angle. Consequently, they could not aim for a specific angle during tilting, and they had to make a difficult comparison of angles across trials to ensure the glasses reached the same point.

The current finding is similar to work by Schooler (Schooler \& EngstlerSchooler, 1990; Schooler, Ohlsson, \& Brooks, 1993) which demonstrated that verbal processes can lead people to focus on some aspects of a visual task at the expense of others. In the case of glass tilting, people focussed on spatial outcomes rather than allowing their knowledge of rate to drive their imagery. Consequently, their spatial beliefs usurped the functional, dynamic component of imagery. These results, however, should not be taken to imply that imagery is always better than beliefs for simple physical problems (cf. McCloskey \& Kohl, 1983). Sholl and Liben (1995), for example, showed that beliefs enable people to compensate for illusory tilts in the Piagetian water level task. Rather, the results indicate that physical imagery can be usurped by beliefs that specify spatial outcomes.

The results suggest a methodological caveat. If people develop beliefs about the spatial outcome of a physical event prior to using physical imagery, as might occur in a think aloud protocol, it may taint their imagery inferences. Even if people know about this contamination risk, it may still be difficult to disregard the beliefs. People may not know whether they are properly conducting the physical imagery or whether they are spatially portraying their beliefs; people have difficulty monitoring the source of their knowledge (Johnson \& Raye, 1981). For example, after hearing the answer, people frequently say they can see the effect and could have solved the problem by exaggerating the effect with a long, narrow tube. They are fooling themselves 
by simply portraying what they just heard. When other people were asked to make a judgment about a test tube versus a large pot, they made the usual judgment errors.

\section{EXPERIMENT 2: BELIEFS ABOUT RATE COMPLEMENT PHYSICAL IMAGERY}

To look for evidence supporting KM, Experiment 1 manipulated people's spatial beliefs without changing dynamic features of the problem. This tested whether spatial expectations drive physical imagery. The results did not support KM. One might argue, however, that people are simply bad at incorporating explicit beliefs into imagery, regardless of whether those beliefs are about spatial outcomes. To address this interpretation and to find evidence for DM, this study determines whether beliefs about rate can be productively incorporated into physical imagery.

People's beliefs about rates were manipulated without changing the spatial features of the problem. People tilted wide and thin glasses while imagining that the glasses contained either water or molasses. According to KM, there should not be any changes in tilting behavior because there are no changes in spatial relations or operations. According to DM, people may exhibit different tilts for water and molasses. Because people believe molasses changes slowly, they may calibrate the rate the imagined liquid changes in response to their rate of tilting. For example, it might take two units of glass change to yield one unit of molasses change. If this is the case, then people should tilt the molasses glasses farther, because it will take more movement to change the molasses than the water. To make sure that people are not simply tilting the molasses glasses farther because they believe that the glasses should end at a greater angle, people were subsequently asked whether they believe glasses with water and molasses need to be tilted different amounts for the liquid to reach their rim.

\section{Method}

Twelve undergraduates participated for partial course credit. Glass width and imagined viscosity were crossed within-subject factors. The wide and thin glasses were $15.5 \mathrm{~cm}$ tall, plastic cylinders with the water level drawn $3.0 \mathrm{~cm}$ below the rim. The thin glass was $3.1 \mathrm{~cm}$ in diameter. The wide glass was $9.5 \mathrm{~cm}$. Using the same directives as Experiment 1, each participant tilted the pair of glasses twice with eyes closed. One time they pretended that the glasses contained water, and one time they pretended that the glasses contained molasses. Half of the participants completed the molasses condition first. The orders of the thin and wide tilts were counter-balanced. After tilting, people decided whether the thin and wide water glasses would start to pour at the same or different times. Finally, they saw two identical wide glasses. They were told to pretend that one holds water and one holds molas- 


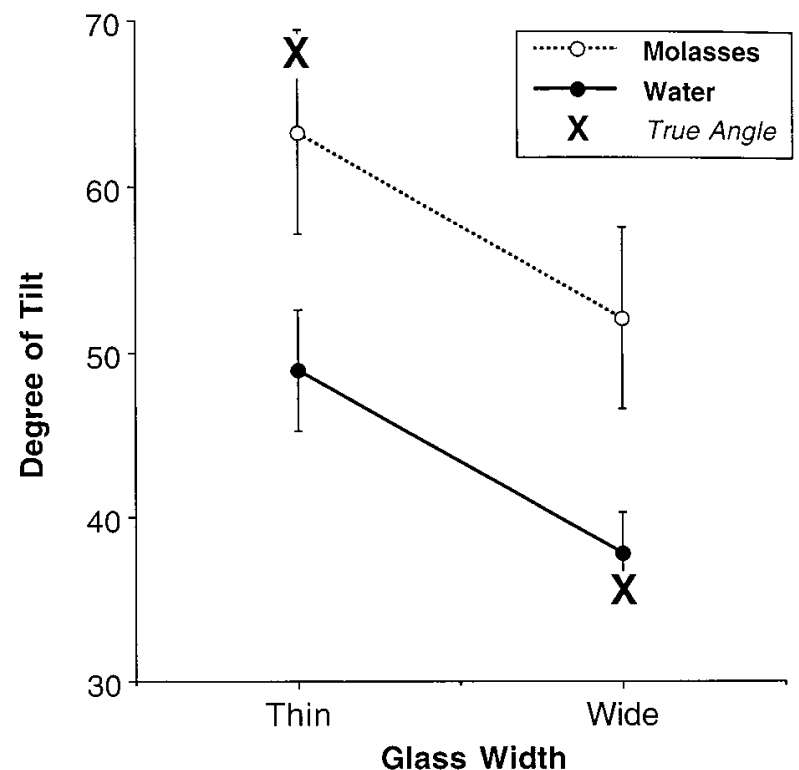

FIG. 4. Imagined viscosity affects physical imagery (Experiment 2).

ses. They verbally answered whether the two glasses would need to be tilted to the same or different angles for the liquids to reach the rim.

\section{Results}

All participants correctly tilted the thin glass farther than the wide glass even though only two of those people explicity believed that the wide glass would pour first. (Nine people said same angle, and one said thin first). More relevant to the current investigation, Fig. 4 shows that the directive to imagine molasses led participants to tilt the glasses farther than when they imagined water. When asked explicitly however, 10 of the 12 individuals said that identical glassed with molasses and water would need to be tilted to the same angle for the liquid to reach the rim.

To perform the statistics, angle of tilt was the dependent measure with width and viscosity as crossed within-subject factors. Task order (molasses or water first) was a between-subjects factor. There is a significant effect of viscosity; $F(1,10)=14.3, M S e=172.9, p<.01$, and a significant effect of glass width; $\mathrm{F}(1,10)=35.1, M S e=42.9, p<.01$. There is no effect of order; $F(1,10)=1.44, M S e=801.6, p>.25$. There is no evidence of interactions; all $F$ 's $<0.3$.

\section{Discussion}

The results support DM over KM. Although molasses- and water-filled glasses have the same geometry, people imagined them behaving differently. People's beliefs about physical properties informed their imagery. People 
included a viscosity representation that slowed the rate at which the imagined liquid responded to their tilting. It is possible that people would not have tilted the molasses glasses so far had they taken more time and given the imagined molasses a chance to react. If this had happened, it too would have shown that physical imagery depends on the coordination of rates because people would have modified the timing of their imagery. But, the fact that people did not slow their tilting to make the glasses end at the same angle underscores a key claim of DM. People rely on the temporal coordinations of physical imagery to allow inferences to emerge; they do not first decide what the inference should be and then adjust the timing of things to portray that inference (e.g., turn a hand more slowly so the molasses glass reaches the same angle as the water glass).

An alternative interpretation is that people's beliefs about molasses were not incorporated into their imagery. Instead, the beliefs caused a spatial adjustment. Maybe after completing the usual tilt through imagery, people decided that they should tilt the glasses a bit farther to take the molasses into account. Although this "imagery plus spatial belief adjustment'" interpretation cannot be ruled out, people explicitly believed that viscosity does not affect the tilt angle. It seems unlikely that they would have made an explicit adjustment against their beliefs. Moreover, there was no evidence of one motion yielding an initial tilt and then a second motion that was intended to compensate for the molasses.

\section{EXPERIMENT 3: PHYSICAL IMAGERY CANNOT IGNORE GRAVITY}

The previous experiments examined how beliefs affected imagery. The next two studies look at the effect of perceptual information. The studies rely on the perception of gravity and its haptic effects. The studies do not examine the effects of visual perception on imagery. There is interesting work that debates whether people use kinematic visual input to create dynamic perceptions (e.g., Gilden, 1991; Hecht, 1996). The question here, however, is whether inherently dynamic perception affects people's physical imagery even if there are few visible changes. If it does, this supports DM.

To examine the effect of gravity, participants completed the pouring task when the glasses started upright as usual or were tipped $90^{\circ}$ sideways. When a glass was sideways, the participants were told to imagine that the water resided in the glass as if it were upright. As they tilted the glass to determine its angle of pouring (as if upright), they were actually tilting the glass upsidedown. Experiment 3a compared tilting accuracy when the glasses were upright and sideways. In Experiment 3b, participants rated the quality of their imagery when they held the glass still and when they tilted the glass. The reasons for these two substudies follow.

Previous treatments of gravity reflect the different emphases of KM and DM. Within the KM framework, research has emphasized gravity's role in defining an up-down spatial coordinate system (e.g., Franklin \& Tversky, 
1990; Gentaz \& Hatwell, 1996). In contrast, DM emphasizes the dynamic, “pulling'" aspect of gravity (e.g., Hecht, Kaiser, \& Banks, 1996; Hubbard, 1995). KM predicts two possibilities, both involving spatial coordinate systems. One alternative is that the imagination can overcome gravitationally perceived vertical. By shifting a coordinate system $90^{\circ}$ in their imagination, people may treat the sideways glass and water as upright with respect to their imagined spatial coordinate system. In this case, people should succeed with the sideways task. Alternatively, people may not be able to shift their coordinate system. In this case, their imagery should be poor. Notably, if they have trouble shifting their coordinate system, then their imagery should be poor both when they hold the glass still and when they tilt the glass. Therefore, people's imagery ratings should be about the same whether the glass is moving or stationary.

According to DM a key aspect of gravity is dynamic; the force of gravity specifies rates and directions of change. Consequently, the effect of gravity on the imagined water in the sideways glass should be strongest when the glass is in the process of change. When the sideways glass is static, the representations that determine the movement of the imagined water are inactive and will not respond to dynamic perceptual information. For example, people can easily imagine a piano in mid-air. But, when the glass moves, the representations must become active to regulate the rate at which the water transforms in the glass. If one supposes that dynamic representations are receptive to dynamic perceptions, it should be very difficult to maintain a mental analog of gravity that conflicts with perceived gravity. Therefore, people's tilts will be inaccurate, and they will rate the quality of their moving image particularly low.

\section{Method}

Experiment $3 a$. Sixteen adult volunteers were randomly assigned to one of two conditions. In the Aligned condition, they held the glass so that its main axis was the same as their bodies'. In the Crossed condition, they held the glass perpendicular to their bodies'. Within each condition, participants tilted a wide and a thin glass both Standing and Lying on their sides (order was counter-balanced). The glasses were upright for Standing-Aligned and Lying-Crossed, and they were sideways for Standing-Crossed and LyingAligned. By employing this crossed design, the effect of gravity is not confounded with glass or body position. When the glasses were sideways with respect to gravity, they were always tilted toward the ground. Participants were told to imagine that the water still resided in the glass as if it were upright. It was suggested that they could imagine the glass being upright, imagine themselves rotated $90^{\circ}$, or imagine gravity operating sideways.

Experiment 3b. Twelve undergraduates participated for partial course credit. They learned a 10-point "imagery quality" rating scale. They learned that a high-quality image (10) has sharp detail and is easy to maintain and control. A low-quality image (1) is hard to see and prevent from fading, and 
it tends to fall apart or run away. To practice the rating scale, the students rated static and dynamic images of varying degrees of complexity. Afterward, each student completed the upright and sideways ratings with order counter-balanced between-subjects. For the upright task, participants were introduced to the task as usual. They closed their eyes, imagined the water, and rated the quality of the water image (not the glass image) without any tilting. They then tilted the glass to bring the imagined water to the rim. Approximately halfway through this tilt, they were interrupted to rate their water imagery. For the sideways version, they held the same glass $90^{\circ}$ from upright while standing. They were given the same instructions about disregarding gravity as in Experiment 3a.

\section{Results}

Figure 5 presents the results from Experiment $3 \mathrm{a}$. When the glasses were upright with respect to gravity, people tilted the thin glass farther than the wide one. In contrast, when the glasses were sideways, people did not. Statistically, a mixed-design crossed the between-subjects factor of glass position (Aligned, Crossed) with the within-subject factors of glass width (thin, wide) and body position (Standing, Lying). The body position by glass position by glass width interaction is significant; $F(1,14)=91.0, M S e=13.36$, $p<.01$. This indicates that participants correctly tilted the thin glass farther than the wide glass when the glasses were environmentally upright (regardless of glass or body position). There is also an uninterpreted main effect of glass position; people tilted a glass less when it crossed their body axis; $F(1,14)=7.5, M S e=508.4, p<.05$.

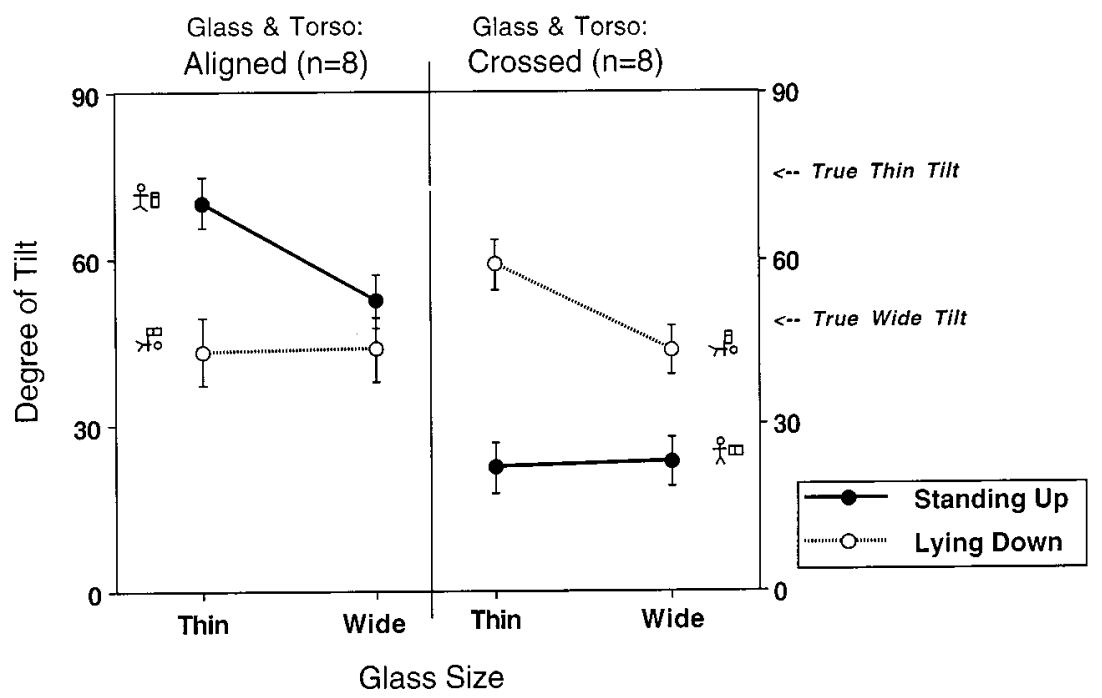

FIG. 5. Tilting against gravity interferes with physical imagery (Experiment 3a). 


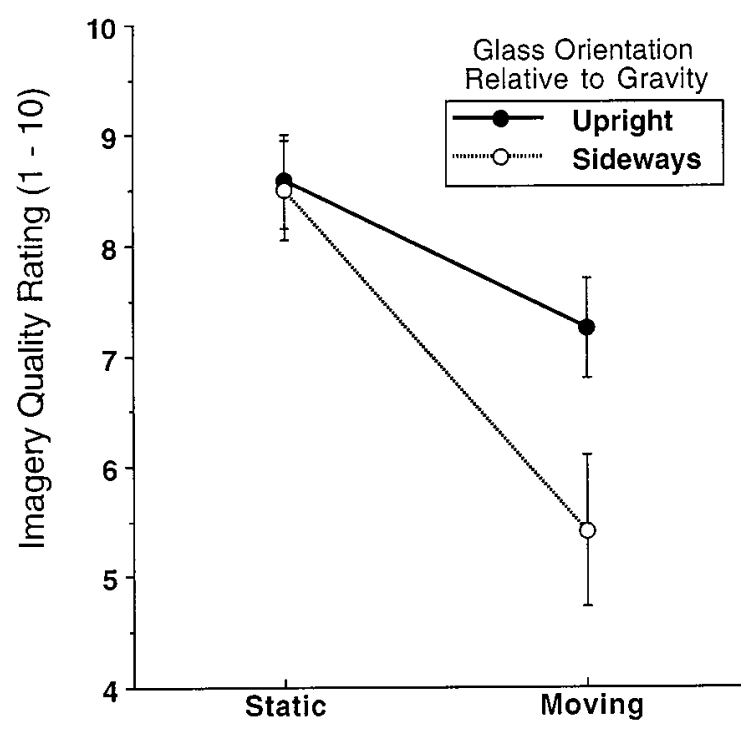

State of Water Image 3b).

FIG. 6. Gravity interferes with a moving image more than a static image (Experiment

Figure 6 shows the ratings from Experiment 3b. When static, the rating of the water image was the same for both the upright and sideways glasses. Despite gravity, participants reported no difficulty with the static sideways image. In contrast, the sideways glass led to markedly poorer image quality when the glass was put in motion. Two quotes capture common sentiments, "The water began to pour out when I started to tilt the glass,' and, "My inner-ear was screaming at me."' To confirm the patterns statistically, a within-subject analysis compared the ratings for the glass orientation by motion combinations. There is a significant interaction indicating that glass orientation had an effect on the moving image but not the static one; $F(1,11)=33.0, M S e=.28, p<.01$. There is also an interpretable main effect indicating that the moving imagery was of poorer quality than static imagery in both conditions; $F(1,11)=19.1, M S e=3.07, p<.01$.

\section{Discussion}

As documented many times, there can be interference between perception and imagery. The current results extend the possible sources of interference to include gravity perception (cf. Franklin \& Tversky, 1990). People did not correctly tilt a thin glass farther than a wide one when the glasses were sideways with respect to gravity. The current results also show that animated physical imagery is particularly prone to interference from gravity. The qual- 
ity of the stationary water image was the same when the glass was upright and sideways. But when put in motion, image quality decayed more in the sideways case. KM would not predict this selective interference because it does not discriminate between moving and static imagery with respect to gravitational forces. DM would predict these results because physical imagery depends on representations that enforce rates of interaction. When there are no movements, these representations are irrelevant. However, when the system is set in motion, the representations are necessary to coordinate the water and glass movement. People had to ignore gravity so the water would not pour out of the glass, but at the same time, they had to imagine gravity so the water would transform correctly with respect to the glass. They evidently could not do this.

The destructive effects of gravity were contingent on the environmental position of the glass and not an individual's body or hand position. This means that gravity's effects were "projected" onto the water and were not simply the effect of perceived hand or body position. Even so, it remains unanswered how completely people can represent gravity. Perhaps, the difficulty people had with imagining the water against gravity was not due to interference. Maybe people simply cannot represent gravity in analog form (e.g., Lackner, 1992). There is hardly a need to represent gravity for perception or action; it is ubiquitous. It is an open question what would happen if people tilted the glasses under weightless conditions where they could try to represent gravity without interference.

\section{EXPERIMENT 4: DYNAMIC PERCEPTION INTERACTS WITH PHYSICAL IMAGERY}

The results of the preceding study favored DM because gravity interfered with people's physical imagery. The study, however, did not keep all spatial variables identical while only changing dynamic ones. Consequently, there is always room for alternative explanations. For example, one might argue that the decay of the water imagery during the sideways tilting was not due to a conflict of dynamic perception and representation. Instead, the imagined movement may have simply added one too many representational burdens to a system that was already taxed by maintaining an unusual coordinate system. Experiment 4 avoids this limitation. In Experiment 4 a participants in two conditions tilted four pairs of wide and thin cylinders with four water levels each. In the Regular condition, individuals tilted the glasses as usual. In the Weight condition, individuals tilted glasses that had weights added to their bases. When tilting these glasses, people rotate the weighted base upward. Like trying to lift a barbell from one end, this causes a perceptible torque (twisting in the hand) that increases as the glass approaches the horizontal. As the torque grows, people must work harder to turn the glass. According to DM, the increasing torque may lead people to transform the water 
faster in their imagination; the rate of water movement may be yoked to the rate of tilting work. If so, people should increasingly under rotate for the lower water levels because they have to tilt farther into the torque effect. $\mathrm{KM}$ does not predict an effect of the weights because spatial relations remain unchanged.

Experiment $4 \mathrm{~b}$ helps to determine the locus of any weight effect demonstrated in Experiment 4a. Without vision, people completed a spatial task by tilting a weighted and a regular glass to the target angle of $45^{\circ}$. If people tilt the weighted glass and the regular glass to the same degree, then the weight does not affect people's spatial imagery of the glass angle. Therefore, any effect of weight in Experiment $4 \mathrm{a}$ must come from the dynamics of coordinating the movement of the water with the movement of the glass. This idea is developed more fully after presenting the data.

\section{Method}

Participants. For Experiment 4a, 30 graduate and undergraduate students participated in the experiment for financial compensation or partial course credit. Students were randomly assigned to condition ensuring a gender balance of 9 females and 6 males in each condition. Experiment $4 \mathrm{~b}$ recruited 16 adult volunteers from the community.

Materials. Eight cylindrical glasses were $15.5 \mathrm{~cm}$ tall. The four thin glasses were $3.1 \mathrm{~cm}$ in diameter and weighed $67 \mathrm{~g}$. The four wide glasses were $9.5 \mathrm{~cm}$ in diameter and weighed $204 \mathrm{~g}$. Each glass had a water level at $1.5,3.0,4.5$, or $6.0 \mathrm{~cm}$ below the rim. For the weighted condition, $97 \mathrm{~g}$ weights were affixed to the center of a recess in the bottom of each glass. Experiment $4 \mathrm{a}$ used all eight glasses. Experiment $4 \mathrm{~b}$ used one weighted and one regular thin glass.

Design and procedures. For Experiment 4a, there were two betweensubjects conditions, Regular and Weight. The crossed diameter and water level factors created eight tilt measures for each. During the tilting phase, people were allowed to grasp the glasses anywhere along their lengths. People saw only one glass at a time in random order and closed their eyes during the tilting. After the tilting phase, individuals made the standard explicit judgment over a pair of thin and wide glasses. For Experiment $4 \mathrm{~b}$, each individual tried to tilt a weighted and a regular thin glass to $45^{\circ}$ in the picture plane with their eyes closed. They did not try to imagine water in the glasses. The order of the glasses was counter-balanced across participants.

\section{Results}

Experiment 4a. Compared to people in the Regular condition, Fig. 7 shows that people in the Weight condition increasingly under rotated the glasses the lower the water level. To show this effect statistically, glass width and water level were crossed within-subject factors and weight condition was a between-subjects factor. The condition by level interaction is significant; 


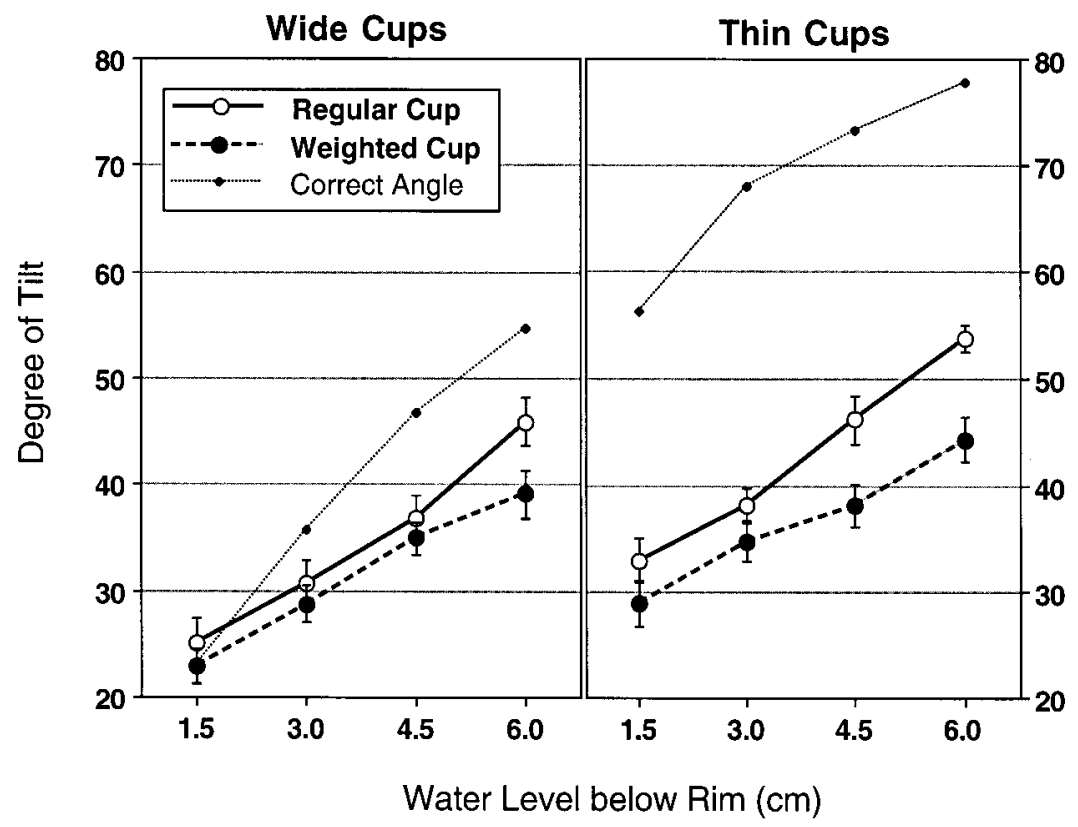

FIG. 7. Weighted glasses are increasingly under tilted relative to regular glasses (Experiment $4 a)$.

$F(3,84)=4.5, M S e=20.7, p<.01$. This indicates that the increasing torque of the larger rotations had an effect on people's physical imagery. The only other effect of condition was that Weight people tended to under rotate the thin glass more than the wide glass overall; $F(1,28)=5.9$, $M S e=24.3, p<.05$.

With respect to the more general results, tilting 4 pairs of glasses did not improve people's subsequent explicit judgments. Only two individuals in the Regular condition and one individual in the Weight condition made the correct judgment. But, as usual, people's tilts had the correct relationships. The thin glasses were tilted farther than the wide glasses for each water level; $F(1,28)=109.1, M S e=24.3, p<.01$. Also, individuals made larger tilts for lower water levels; $F(3,84)=181.0, M S e=20.1, p<.01$.

Experiment $4 b$. For this study, a new set of individuals tried to tilt a regular glass and a weighted glass to the angle of $45^{\circ}$ without vision. People were quite accurate in both conditions; unweighted $M=46.6^{\circ}, S D=4.2$; weighted $M=46.2^{\circ}, S D=5.0$. There was little indication that the weight caused people to under-rotate the glass as it had for Experiment $4 \mathrm{a}$. There was no statistical effect of weight; $F(1,15)=.19, M S e=5.9, p>.6$, and only one of the 16 individuals tilted the weighted glass $5^{\circ}$ less than the regular glass. 


\section{Discussion}

Relative to the Regular condition, individuals in the Weight condition of Experiment $4 \mathrm{a}$ increasingly under-tilted the glasses the farther they were rotated. As the weighted glasses approached the horizontal, they generated increasing torque. The greater this torque became, the less people turned their glass. Like the gravity study of Experiment 3, this study shows that dynamic perceptual information enters into dynamic imagery even when it is invisible and no spatial information has changed.

Experiment 4a showed that perceived weight affects physical imagery. While this result supports DM over KM, one last piece of evidence is needed to solidify the interpretation. KM claims that an image is regulated by spatial information. By this model, dynamic perception can affect imagery only if it is translated into a spatial implication that can be represented in an image. So, by this translation model, the torque may have caused people to portray each glass at too great an angle; people imagined that the glasses had rotated farther than their hand had actually moved (e.g., Weber \& Dallenbach, 1929). This in turn made them update their representation of the water so it would maintain the desired angle with respect to the glass.

By the translation account, the weights influenced people's representation of the glass angle, and the glass angle influenced people's representation of the water. Experiment $4 \mathrm{~b}$ tested whether the weights caused people to misrepresent the glass angle. Participants tried to turn a glass to a prespecified angle with and without weights. People tilted the weighted and unweighted glasses to nearly identical angles. These results show that the weights do not cause people to misrepresent the angle per se, and therefore, KM cannot explain the effect of torque by positing a mistranslation of dynamic perception into spatial imagery.

In contrast to the translation model of KM, DM proposes a direct representation model of how haptic perception can influence physical imagery. One might characterize the direct relationship as: $\Delta$ perceived work of turning the glass $\leftrightarrow \Delta$ imagined displacement of water. The increasing work rate caused the water to deform faster in the imagination. This DM relationship does not predict an effect of the weight when aiming for the $45^{\circ}$ target because, for this task, people are not relying on rate information to coordinate interacting motions.

In the direct representation model, notice that the torque and water movement "units" are not the same types of information; the former is dynamic and the latter is spatial. Although different, they can be related through a higher order balancing of rates. Unlike $\mathrm{KM}$ which requires the translation of all information into the same spatial code, DM allows different formats of information to interact if they are rate-based (e.g., inches per second with foot-pounds per second). This has some theoretical appeal. Physical imagery can use the same mechanisms to respond to rate information whether that 
information is formatted by haptics or by the operations of the image itself. This puts physical imagery in a seamless relationship with perception.

\section{GENERAL DISCUSSION}

\section{Empirical Summary}

Four experiments investigated people's imagery for liquid in a glass to test two proposals for how people model physical interactions through imagery. The kinematic model (KM) proposes that an image represents and manipulates spatial information by maintaining or targeting certain geometric relationships during transformation. The way to affect the outcome of an imagery simulation is to alter the spatial relations being modeled. The dynamic model (DM) proposes that an image also represents physical information in the form of rates that coordinate the interactions among imagined objects. Under this model, even if no spatial relations are altered, imagery simluations may be altered by changes to rate representations and by perceptions of forces. The results support DM. In Experiment 1, participants thought explicitly about the spatial outcome of the task before tilting the glasses. Rather than enhancing their imagery per KM, it undermined their ability to complete the task through physical imagery, presumably because focussing on a spatial outcome short-circuited the rate information that people normally use to solve the problem. In Experiment 2, people tilted glasses containing imagined molasses farther than glasses containing imagined water, even though no spatial relations differed and participants stated afterward that water and molasses yield the same angle. In Experiment 3, people could not complete the pouring task successfully when the glass started sideways with respect to gravity. The interference of gravity appeared when people imagined the water moving but not when it was static. This fits the DM story because constraints on rate would only be expected to have an effect during motion (but see, Freyd, Pantzer, \& Cheng, 1988). Finally, in Experiment 4, individuals tilted weighted or unweighted glasses. The weights did not change the spatial properties of the problem, and when people were asked to tilt the glasses to a specific angle the weights had no influence. But, in the context of the weighted pouring task, the lower the water level, the more people under-rotated a glass. The weights generated an increase in the torque of the glasses as they approached the horizontal. This accelerating torque led people to imagine they were changing the situation faster than they actually were. All told, the evidence is consistent with the DM framework, and pending extension to other tasks and the illumination of contributing factors, the results support the dynamic quality of people's physical imagery.

\section{Implications of the Dynamic Model for Theories of Imagery}

$\mathrm{KM}$ derives from theories of imagery that have taken their cue from visual perception. The similarity between models in the imagination and vision is 
frequently invoked as a criterion for demonstrating imagery (Perky, 1910; Finke, 1980; Kosslyn, 1976). There is a large body of research indicating that people can use visual imagery to reason about shape, position, change of perspective, and navigation. This visual-spatial research agenda, however, brings with it an emphasis that may not be well-suited to physical imagery. For example, it emphasizes the simulation of the visual consequences of imagined actions rather than the actions themselves. Although people surely "see" the behavior of the glass in their mind's eye, this may not be the psychologically important property of physical imagery that needs explaining. In fact, as it turns out, people are not precisely aware of how the glass "looks" in their imagination during the water pouring task (Schwartz \& Black, 1999). Consider, for example, what happens when people are given a chance to adjust the angle of a glass after they open their eyes. When people complete the spatial task of tilting a narrow glass to $60^{\circ}$ without vision, they will not make any adjustments when they open their eyes. However, for the water pouring task, people consistently adjust a narrow glass forward when they open their eyes. Evidently, people's physical imagery for the glass does not correspond to its visual realization.

The current work raises a set of questions that are not frequently addressed in the imagery literature because of its common emphasis on imagery as a derivative of vision. For example, the Discussion of Experiment 4 had to address the question of how people incorporate dynamic, haptic perception into their imagery. This is not a pressing question if one views imagery as a subset of vision. Other novel questions include the role of invisible properties in knowledge emergence, the role of learning in developing the repertoire of available imagery transformations, and the integration of beliefs into imagery. The following paragraphs offer some initial thoughts on these issues by developing a more detailed treatment of how people represent rate.

The representation of rate. Thus far, the coordination of rates has been explained with a simple qualitative formula. This formalization does not provide any mechanism by which this coordination occurs. Schwartz and Black (1996a) describe a possible mechanism in their account of depictive models. A depictive model is a computer implementation of physical imagery based on the object-oriented paradigm of computer programming. In a depictive model, the primary ontological entity is not a spatial array. Instead, it is an imagined object that includes rate constraints and that sends real-time "messages" that indicate its rate of change.

The rate constraints of an imagined object determine the rate at which the object responds to other rates. For example, a "spongy constraint" may make the object deform quickly when exposed to an imagined rate of surface pressure. There are different computational ways to represent rate constraints. One might, for example, represent the elasticity of an object by using surface vectors, the length of which determines "springiness" and the 
direction of which determines the direction of resilience. For the current purposes, the important assumption about rate constraints is that they are timing-responsive representations (TRs). TRs respond to real-time temporal information that specifies change. In the object-oriented paradigm of depictive models, temporal information takes the form of messages that are passed from imagined object to imagined object, or from perception to imagined object. The frequency (and intensity) of messages conveys the rate of change. For example, tilting the glass generates a series of change messages; the representation of the water uses this timing information to regulate its transformation to the rim of the glass. For the weighted glasses of Experiment 4 , the torque increased the frequency with which the wrist sent change messages to the representation of the water. This caused the water to change more frequently (faster).

The information contained in TRs is encapsulated, meaning that it can only be accessed through the TRs' manifest effects on object behavior. The way to gain access to the information embodied in TRs is to try to change the imagined object and then let the TRs determine how the object will change. In this regard, a depictive model is something like interacting with the physical world where people might poke an object to see how resilient it is. So, whereas one might say that spatial imagery is a form of simulated viewing, physical imagery is a form of simulated doing; people imagine perturbing physical objects to gather information. The following sections use depictive models and their TRs to explain some of the questions raised by the current work.

Emergence through imagined action. One question that the current work raises is why the action of turning the glasses is so important for the emergence of the correct solution. People do not know the solution before tilting the glasses nor after tilting the glasses, but only through their tilting. It is not motor activity per se that causes this effect (e.g., Bridgeman, 1992). The results are similar when people simply imagine tilting the glasses (Schwartz \& Black, 1999).

TRs help explain why people need the real or imagined action of turning the glasses. TRs require the timing information generated by (imagined) actions to model the behavior of the water in the thin and wide glasses. Beliefbased representations cannot directly access the relevant rate information because beliefs are proposals about change and not instances of change. Beliefs have an arbitrary relation to real time; the expression of a belief about a slow action, for example, can itself be slow or fast. People evidently have some awareness that (imagined) actions can harness knowledge that is inaccessible to their belief system. Schwartz and Black (1996b), for example, found that people spontaneously use hand gestures and dynamic imagery when their beliefs fall short (see also, Alibali \& DiRusso, in press; GoldinMeadow, Alibali, \& Church, 1993; Schwartz \& Hegarty, 1996). 
Learning and imagery. The research showed that people could change the imagined viscosity of the liquid when told it was molasses. Presumably this was based on their experiences with molasses. How might learned knowledge like this add to the repertoire of transformations available to imagery? The acquisition of image operators is an important question for physical imagery because people should be able to model a broad range of physical interactions like floating and grinding. The depictive model of physical imagery provides one possible mechanism. Learning alters how TRs respond to a change message. Gardin and Meltzer (1989), for example, created a computer model in which a series of rings were placed in a chain. Each ring had a constraint on how easily it could pivot around the contact point it made with an adjacent ring. By making the constraint minimally responsive, the rings modeled a rigid rod, and by making the constraint highly responsive, they modeled a limp string. By this scheme, quantitative changes to the responsiveness of a TR can model qualitatively different phenomena.

TRs may also explain how experience can tune imagery. Learning causes the recalibration of responsiveness. Imagine, for example, asking people to step in a circle on a turntable. As people step in one direction, the turntable rotates slowly in the opposite direction. The subjective experience is the rotational equivalent of walking the wrong direction on a moving sidewalk; one perceives less movement than usual per step. After a few minutes, people naturally recalibrate the mental coupling between their rate of stepping and the mental maps they use to monitor their orientation (Rieser, 1990). For example, when taken off the turntable and asked to turn to face a target at $180^{\circ}$ without vision, people unwittingly turn too far; they update their mental maps according to the progress they would have made on the moving turntable. Schwartz and Berry (1998) found evidence that the recalibration effect is due to people changing the timing responsiveness of their mental maps. Recalibration effects primarily appeared when people generated a series of timing messages through their actions. For example, people overshot a target at $135^{\circ}$ when they stepped to face the target or when they swiveled at the waist to face the target. But, when people turned with a single jump to face the target or raised their hand in a ballistic motion to point at the target, the effect of recalibration was significantly diminished. Compared to stepping and swiveling, the latter ballistic motions did not generate a series of timing messages. Therefore, people's TR maps did not respond and people did not show the effects of recalibration.

Imagery, beliefs, and perceptions. A final relevant property of depictive models is that they help address the experimental results that showed that people's imagery interacted with their beliefs and perceptions. Recall that in the Judge $\rightarrow$ Tilt condition of Experiment 1, people's beliefs interfered with their imagery, but in the molasses study of Experiment 2, people's beliefs were incorporated into their imagery. According to depictive models, beliefs are able to introduce or modify rate constraints when an image is 
constructed (through standard priming mechanisms). For example, people changed the timing responsiveness of the imagined liquid according to their belief that molasses is less responsive to movement than water. But, beliefs about the spatial outcomes of constraints on movement (e.g., the final angle of the glass) cannot be incorporated when an image is actively modelling dynamics. Beliefs cannot assert spatial outcomes without undermining the functionality of TRs in determining those outcomes. Thus, in Experiment 2, people's beliefs about the spatial outcomes of the task were destructive to their dynamic imagery.

With regard to perceptual information, people ignored gravity to maintain a stationary image of the sideways water, and they disregarded the weights when aiming for a $45^{\circ}$ angle. However, when they put a glass in motion, the gravity overwhelmed their sideways imagery, and the torque of the weighted glasses influenced their tilts. These results make sense if one assumes that when people's imagery is stationary or solely spatial, the TRs that coordinate interactions among imagined objects are not active. Therefore, they are not responsive to perceptual rate information. But, once the TRs are active in regulating the motions in an image, they become responsive to real-time rate information (as in the case of the turntable study).

To put the implications of depictive models more simply, beliefs can be incorporated into imagery early in the inferential pathway, whereas perception becomes dominant later in the dynamic portion of a physical inference. This conclusion offers a refinement to current theories of concept-percept integration that do not differentiate between the stationary and moving aspects of analog representations (e.g., Barsalou, in press; Intons-Peterson, 1993; Tabachneck, Leonardo, \& Simon, 1997). The conclusion also makes sense in that one would expect perception to have the final word when people dynamically interact with the physical world. Yet, imagery is not the same thing as perception, and there should be room for people to see how their beliefs play out when modeled in the imagination without perceptual input.

\section{Conclusion}

Theories of spatial imagery and image kinematics often concern the similarity between visual experience and representation. For these theories, it is not important to represent physical causality because the theories do not explain how people change the physical world to reach instrumental and informational goals (cf. Kirsh \& Maglio, 1994). But, for a theory of physical imagery, the representation of physical properties and dynamics is fundamental. This is because physical imagery may stem from doing and not from viewing. When people take action in the world, they need to understand physical properties to help further their actions. The hypothesis here is that physical imagery incorporates rate-based representations that allow people to anticipate and respond to how their physical actions affect and are affected by a dynamic world filled with forces and resistances. 


\section{REFERENCES}

Alibali, M. W., \& DiRusso, A. A. (in press). The function of gesture in learning to count: More than keeping track. Cognitive Development.

Aglioti, S., Desouza, J. F. X., \& Goodale, M. A. (1995). Size-contrast illusions deceive the eye but not the hand. Current Biology, 5, 679-685.

Barsalou, L. W. (in press). Perceptual symbol systems. Behavioral and Brain Sciences.

Bridgeman, B. (1992). Conscious vs. unconscious processes: The case of vision. Theory \& Psychology, 2, 73-88.

Chase, W. G., \& Clark, H. H. (1972). Mental operations in the comparisons of sentences and pictures. In L. W. Gregg (Ed.), Cognition in learning and memory. New York: Wiley.

Decety, J., Jeannerod, M., \& Problanc, C. (1989). The timing of mentally represented actions. Behavioural Brain Research, 34, 35-42.

Drake, S. (1989). Introduction. In G. Galileo, Two new sciences including centers of gravity and force of percussion (pp. xii-xxxv). Translation by Stillman Drake, 2nd Edition. Toronto: Wall \& Thompson.

Finke, R. A. (1980). Levels of equivalence in imagery and perception. Psychological Review, 87, 113-132.

Finke, R. A. (1985). Theories relating mental imagery to perception. Psychological Bulletin, 98, 236-259.

Finke, R. A., \& Freyd, J. J. (1989). Mental extrapolation and cognitive penetrability: Reply to Ranney and proposals for evaluative criteria. Journal of Experimental Psychology: General, 188, 403-408.

Forbus, K. D., Nielsen, P., \& Faltings, B. (1990). Qualitative kinematics: A framework. In D.S. Weld and J. de Kleer (Eds.), Reading qualitative reasoning about physical systems. San Mateo, CA: Morgan Kaufman.

Franklin, N., \& Tversky, B. (1990). Searching imagined environments. Journal of Experimental Psychology: General, 119, 63-76.

Freyd, J. J. (1987). Dynamic mental representations. Psychological Review, 94, 427-438.

Freyd, J. J., Pantzer, T. M., \& Cheng, J. L. (1988). Representing statics as forces in equilibrium. Journal of Experimental Psychology: General, 117, 395-407.

Freyd, J. J., \& Johnson, J. Q. (1987). Probing the time course of representational momentum. Journal of Experimental Psychology: Learning, Memory, and Cognition, 10, 126-132.

Funt, B. V. (1980). Problem-solving with diagrammatic representations. Artificial Intelligence, 13, 201-230.

Gardin, F., \& Meltzer, B. (1989). Analogical representations of naive physics. Artificial Intelligence, 38, 138-159.

Genatz, E., \& Hatwell, Y. (1996). Role of gravitational cues in the haptic perception of orientation. Perception \& Psychophysics, 58, 1278-1292.

Gentner, D., Brem, S., Ferguson, R., Markman, A. B., Levidow, B. B., Wolff, P., \& Forbus, K. D. (1997). Analogical reasoning and conceptual change: A case study of Johannes Kepler. Journal of the Learning Sciences, 6, 3-40.

Gilden, D. (1991). On the origins of dynamical awareness. Psychological Review, 98, 554-568.

Goldin-Meadow, S., Alibali, M. W., \& Church, R. B. (1993). Transitions in concept acquisition: Using the hand to read the mind. Psychological Review, 100, 279-297.

Hecht, H. (1996). Heuristics and invariants in dynamic event perception: Immunized concepts or nonstatements? Psychonomic Bulletin and Review, 3, 61-70.

Hecht, H., Kaiser, M. K., \& Banks, M. S. (1996). Gravitational acceleration as a cue for absolute size and distance. Perception \& Psychophysics, 58, 1066-1075. 
Hecht, H., \& Proffitt, D. R. (1995). The price of experience: Effects of experience on the water-level task. Psychological Science, 6, 90-95.

Hegarty, M. (1992). Mental animation: Inferring motion from static displays of mechanical systems. Journal of Experimental Psychology: Learning, Memory \& Cognition, 18, 1084-1102.

Hegarty, M., \& Just, M. A. (1993). Constructing mental models of machines from text and diagrams. Journal of Memory and Language, 32, 717-742.

Hubbard, T. L. (1995). Cognitive representations of motion: Evidence for friction and gravity analogues. Journal of Experimental Psychology: Learning, Memory, and Cognition, 21, 241-254.

Intons-Peterson, M. J. (1993). Imaginal priming. Journal of Experimental Psychology: Learning, Memory, and Cognition, 19, 223-235.

Intons-Peterson, M. J., \& Roskos-Ewoldsen, B. B. (1989). Sensory-perceptual qualities of images. Journal of Experimental Psychology: Learning, Memory, and Cognition, 15, $188-199$.

Johnson, M. K., \& Raye, C. L. (1981). Reality monitoring. Psychological Review, 88, 67-85.

Kirsh, D., \& Maglio, P. (1994). On distinguishing epistemic from pragmatic action. Cognitive Science, 18, 513-549.

Kosslyn, S. M. (1976). Can imagery be distinguished from other forms of internal representation? Evidence from studies of information retrieval times. Memory and Cognition, 4, 291-297.

Kosslyn, S. M. (1980). Image and mind. Cambridge: MA, Harvard University Press.

Krist, H., Fieberg, E. L., \& Wilkening, F. (1993). Intuitive physics in action and judgment: The development of knowledge about projectile motion. Journal of Experimental Psychology: Learning, Memory, \& Cognition, 19, 952-966.

Lackner, J. R. (1992). Spatial orientation in weightless environments. Perception, 21, 803-812.

Leyton, M. (1989). Inferring causal history from shape. Cognitive Science, 13, 357-387.

McAfee, E. A., \& Proffitt, D. R. (1991). Understanding the surface orientation of liquids. Cognitive Psychology, 23, 483-514.

McCloskey, M., \& Kohl, D. (1983). Naive physics: The curvilinear impetus principle and its role in interactions with moving objects. Journal of Experimental Psychology: Learning, Memory, and Cognition, 9, 146-156.

McGhee, R. B. (1983). Vehicular legged locomotion. In G. N. Saridis (Ed.), Advances in automation and robotics. New York: JAI Press.

Mills, R. (1994). Space, time and quanta: An introduction to contemporary physics. New York: W. H. Freeman.

Olivier, P., Nakata, K., \& Landon, M. (1996). Multi-level molecular representation. In J. S. Gero and F. Sudweeks (Eds.), Artificial Intelligence in Design (pp. 3-20). Netherlands: Kluwer Academic Publishers.

Parsons, L. M. (1994). Temporal and kinematic properties of motor behavior reflected in mentally simulated action. Journal of Experimental Psychology: Human Perception and Performance, 20, 709-730.

Pascual-Leone, J., \& Morra, S. (1991). Horizontality of water level: A neo-Piagetian developmental review. Advances in child development and behavior, 23, 231-273.

Perky, C. W. (1910). An experimental study of imagination. American Journal of Psychology, 21, 422-452.

Proffitt, D. R., Kaiser, M. K., \& Whelan, S. M. (1990). Understanding wheel dynamics. Cognitive Psychology, 22, 342-373. 
Pylyshyn, Z. W. (1973). What the mind's eye tells the mind's brain: A critique of mental imagery. Psychological Bulletin, 80, 1-24.

Pylyshyn, Z. W. (1981). The imagery debate: Analog media versus tacit knowledge. In N. Block (Ed.), Imagery. Cambridge, MA: The MIT Press.

Raibert, M. H. (1986). Legged robots that balance. Cambridge, MA: The MIT Press.

Rieser, J. J. (1990). Development of perceptual-motor control while walking without vision: The calibration of perception and action. In H. Bloch and B. I. Bertenthal (Eds.), Sensorymotor organizations and development in infancy and early childhood. Dordrecht, Netherlands: Kluwer.

Schooler, J. W., \& Engstler-Schooler, T. Y. (1990). Verbal overshadowing of visual memories: Some things are better left unsaid. Cognitive Psychology, 17, 36-71.

Schooler, J. W., Ohlsson, S., \& Brooks, K. (1993). Thoughts beyond words: When language overshadows insight. Journal of Experimental Psychology: General, 122, 166-183.

Schwartz, D. L., \& Berry, D. (1998). Timing-responsive spatial maps. Unpublished manuscript.

Schwartz, D. L., \& Black, T. (1999). Inferences through imagined actions: Knowing by simulated doing. Journal of Experimental Psychology: Learning, Memory, and Cognition, 25, $1-21$.

Schwartz, D. L., \& Black, J. B. (1996a). Analog imagery in mental model reasoning: Depictive models. Cognitive Psychology, 30, 154-219.

Schwartz, D. L., \& Black, J. B. (1996b). Shuttling between depictive models and abstract rules: Induction and fallback. Cognitive Science, 20, 457-497.

Schwartz, D. L., \& Hegarty, M. (1996). Coordinating multiple representations for reasoning about mechanical devices. In P. L. Olivier (Ed.), Spring symposium on cognitive and computational models of spatial representations. Stanford, CA: AAAI Press.

Shepard, R. N. (1984). Ecological constraints on internal representation: Resonant kinematics of perceiving, imagining, thinking, and dreaming. Psychological Review, 91, 417-447.

Shepard, R. N. (1994). Perceptual-cognitive universals as reflections of the world. Psychonomic Bulletin and Review, 1, 2-28.

Shepard, R. N., \& Cooper, L. A. (1986). Apparent motion. In R. N. Shepard \& L. A. Cooper (Eds.), Mental images and their transformations (pp. 303-324). Cambridge, MA: The MIT Press.

Shiffrar, J. (1994). When what meets where. Current Directions in Psychological Science, 3, 96-100.

Shiffrar, M., \& Freyd, J. J. (1990). Apparent motion of the human body. Psychological Science, 1, 257-264.

Sholl, M. J., \& Liben, L. S. (1995). Illusory tilt and Euclidean schemes as factors in performance on the water-level task. Journal of Experimental Psychology: Learning, Memory, and Cognition, 21, 1624-1638.

Sims, V. K., \& Hegarty, M. (1997). Mental animations in the visuospatial sketchpad: Evidence from dual-task studies. Memory \& Cognition, 25, 321-332.

Tabachneck, H. J. M., Leonardo, A. M., \& Simon, H. A. (1997). CaMeRa: A computational model of multiple representations. Cognitive Science, 21, 305-350.

Turvey, M. T., Solomon, H. Y., \& Burton, G. (1989). An ecological analysis of knowing by wielding. Journal of the Experimental Analysis of Behavior, 52, 387-407.

Tversky, B. \& Schiano, D. J. (1989). Perceptual and conceptual factors in distortions in memory for graphs and maps. Journal of Experimental Psychology: General, 118, 387-398.

Weber, C. O., \& Dallenbach, K. M. (1929). The properties of space in kinaesthetic fields of force. American Jouranl of Psychology, 49, 95-105.

Accepted November 4, 1998 